\title{
EL QUIJOTE EN EL ÁREA DE LENGUA CASTELLANA Y LITERATURA: UNA PROPUESTA DIDÁCTICA
}

\author{
QUIXOTE IN THE AREA OF CASTILIAN LANGUAGE AND \\ LITERATURE: A METHODOLOGICAL PROPOSAL
}

\author{
MARTA LILLO FERNÁNDEZ \\ UNIVERSIDAD DE CASTILLA-LA MANCHA \\ martake7@gmail.com
}

\section{RESUMEN}

El objetivo de este artículo consiste ofrecer una serie de actividades basadas en la obra literaria el Quijote, las cuales permiten no solamente fomentar el hábito lector, sino también que el alumnado desarrolle la competencia lingüística y amplíe sus conocimientos sobre la novela de Cervantes.

PALABRAS CLAVE

Didáctica, Literatura infantil, Quijote, Adaptaciones

\section{ABSTRACT}

The aim of this article consists in offering several activities based on the literary work Don Quixote, which allow not only to foment reading habit, but also to develop the linguistic and literary competence in order that students get to know the novel written by Cervantes.

KEY WORDS

Didactics, Children's literature, Quixote, Adaptations 


\section{INTRODUCCIÓN}

Las grandes obras de la literatura pueden ser adaptadas para utilizarlas en los ámbitos escolares y en las aulas de Educación Primaria, siempre desde el profundo respeto a la obra original, pero teniendo en cuenta las características y edades de los lectores a través de un lenguaje cercano y comprensible. La obra literaria el Quijote de Miguel de Cervantes es uno de los clásicos que se ha traducido a más lenguas y que se ha adaptado en diferentes formatos con la finalidad de dar respuesta a una gran diversidad de receptores, especialmente en el ámbito de la literatura infantil.

"Para lograr que un lector infantil o juvenil muestre interés por la obra de Miguel de Cervantes, necesitamos proporcionarle un conocimiento previo de la obra a través de juegos o recreaciones de la obra original. Además, esta necesidad se enfrenta con la falta de unos adecuados estudios sociológicos de la literatura infantil y juvenil" (García Padrino, 2005, 132-133). Por otra parte, "debemos fomentar la aparición de recreaciones o versiones de la obra original destinadas a los más jóvenes que abarquen desde modificaciones de la obra a los más estimulantes juegos literarios con la finalidad de generar en el lector un conocimiento previo" (García Padrino, 2005, 146).

Además, el Quijote nos ofrece múltiples posibilidades que contribuyen al desarrollo de las competencias básicas establecidas en el Decreto 54/2014, por el que se establece el currículo básico de la Educación Primaria en la comunidad autónoma de Castilla-La Mancha. La obra de Miguel de Cervantes ofrece un amplio abanico de aventuras que le suceden a don Quijote, algunas de ellas muy llamativas para el alumnado, si se saben adaptar a sus intereses. "Algunas de estas aventuras las podemos llevar a las aulas de Educación Primaria a través de cuentos, actividades y materiales complementarios, como por ejemplo la utilización de las nuevas tecnologías aplicadas a la obra cervantina" (García Carcedo, 2005, 122). "La mejor manera de introducir la figura de don Quijote en las aulas es a través de la técnica del cuento, el cual narre algunas de las aventuras quijotescas, sin siquiera ilustraciones, ya que a los niños les emocionan estas aventuras mucho más que a los adultos por su capacidad para el juego simbólico" (García Carcedo, 2005, 126-127).

Antonio Mendoza Fillola $(2005,195)$ destaca la importancia de presentar "sugerencias didácticas que hagan de la lectura y de la documentación un pretexto para hablar sobre el Quijote en el aula, es decir, hablar, opinar, comentar, preguntarse, valorar, interpretar, criticar, etc." Todo este proceso de lectura-interpretación contribuye al desarrollo de la competencia en 
comunicación lingüística, que es uno de los principales objetivos a desarrollar en este artículo. Además, este autor mantiene que debemos introducir la novela de Cervantes en el aula de una manera motivadora para facilitar la comprensión y lectura de su valor literario, cultural y lúdico, lo cual exige la "elaboración de una eficaz propuesta de intención y base didáctica que envuelva al alumno-lector en un proceso de construcción de conocimiento a partir de todo tipo de actividades, y no solo de lectura, sino también de reflexión, documentación y búsqueda que contribuyan al desarrollo de la creatividad" (Mendoza Fillola, 2005, 195).

También Antonio Rey Hazas es partidario de la enseñanza de la literatura a través de la comunicación sin necesidad de teoría. Además, "los clásicos literarios cuentan con la ventaja de que no implican el mismo esfuerzo intelectual de comprensión y atraen la atención del lector por su apariencia de vida, y así, viviendo otras experiencias, participando de otras vidas, el lector aprende sin esfuerzo lo que es una teoría compleja" (Rey Hazas, 2006, 117).

Este artículo presenta una unidad didáctica cuyo eje vertebrador es la obra literaria el Quijote, la cual podemos utilizar en el área de Lengua castellana y literatura con los alumnos y alumnas de segundo curso de Educación Primaria. Por lo tanto, basándonos en las ideas anteriormente expuestas, las actividades que se muestran a continuación permiten al alumnado no solamente fomentar su hábito lector y gusto por la lectura y escritura, sino también conocer la obra de Miguel de Cervantes así como desarrollar ciertos objetivos y contenidos recogidos en el Decreto 54/2014, por el que se establece el currículo básico de la Educación Primaria en la Comunidad Autónoma de Castilla-La Mancha.

\section{JUSTIFICACIÓN CURRICULAR}

A continuación, se exponen los objetivos generales de etapa que desarrollaremos en esta unidad didáctica, los cuales quedan recogidos en el Decreto 54/2014:

a) Conocer y apreciar los valores y normas de convivencia, aprender a obrar de acuerdo con ellas, prepararse para el ejercicio activo de la ciudadanía y respetar los derechos humanos, así como el pluralismo propio de una sociedad democrática.

b) Desarrollar hábitos de trabajo individual y de equipo, de esfuerzo y responsabilidad en el estudio así como actitudes de confianza en sí 
mismo, sentido crítico, iniciativa personal, curiosidad, interés y creatividad en el aprendizaje.

e) Conocer y utilizar de manera apropiada la lengua castellana y desarrollar hábitos de lectura.

i) Iniciarse en la utilización, para el aprendizaje, de las Tecnologías de la Información y la Comunicación desarrollando un espíritu crítico ante los mensajes que reciben y elaboran.

j) Utilizar diferentes representaciones y expresiones artísticas e iniciarse en la construcción de propuestas visuales y audiovisuales.

La siguiente tabla muestra los contenidos del segundo curso de Educación Primaria que desarrollaremos en esta unidad didáctica, los cuales quedan recogidos en el Decreto 54/2014, concretamente en el área de Lengua castellana y literatura.

\section{BLOQUE 1: COMUNICACIÓN ORAL: ESCUCHAR, HABLAR Y CONVERSAR}

1. Interacción en situaciones comunicativas.

2. Participación en el intercambio verbal.

3. Comprensión de mensajes en diferentes situaciones de comunicación oral.

4. Escucha y reproducción de textos breves y sencillos que estimulen la curiosidad e imaginación del alumnado.

5. Dramatización de textos adaptados.

$$
\text { BLOQUE 2: COMUNICACIÓN ESCRITA: LEER }
$$

6 . Interés y gusto por la lectura.

7. Interiorización en la lectura como instrumento de aprendizaje.

8. Utilización de estrategias que mejoren la comprensión (lectura comprensiva). BLOQUE 3: COMUNICACIÓN ESCRITA: ESCRIBIR

9. Producción de textos escritos.

BLOQUE 4: CONOCIMIENTO DE LA LENGUA

10. Adquisición de vocabulario.

11. Conocimiento del abecedario e iniciación al orden alfabético.

12. Palabras derivadas. (Formación de palabras antónimas añadiendo el prefijo in-).

13. Aplicación de normas ortográficas a las producciones escritas. ( $M$ antes de $\mathrm{p} \mathrm{y} \mathrm{b}$ ).

14. Iniciación en el uso de las tecnologías de la Información y Comunicación como instrumento de aprendizaje en tareas sencillas. BLOQUE 5: EDUCACIÓN LITERARIA

15. El texto literario como fuente de comunicación, de placer, de juego, de entretenimiento, de aprendizaje.

16. La literatura: Textos literarios y textos no literarios. El cuento. El teatro. Poesía.

17. Textos propios de la tradición literaria.

Tabla 1. Contenidos del $2^{\circ}$ curso de Educación Primaria del área de Lengua Castellana y Literatura. Decreto 54/2014. 


\section{PRIMERA SESIÓN. ACTIVIDADES DE MOTIVACIÓN PARA DETECTAR LOS CONOCIMIENTOS PREVIOS DEL ALUMNADO}

Esta sesión tiene por finalidad desarrollar los objetivos generales de etapa a), b) y e), así como, trabajar los contenidos $1,2,3,4,6,7,8$ y 15 de la tabla anterior.

\section{¿QUIÉN ES QUIÉN? QUIJOTE’S VERSION}

Esta actividad está basada en el juego original “QQuién es Quién?" pero, en esta ocasión, el juego ofrece algunos de los personajes más relevantes del Quijote. En primer lugar, seleccionaremos un personaje y el alumnado irá realizando preguntas hasta averiguar entre todos dicho personaje. Esta actividad también puede adoptar otras variables (parejas, grupos, etc.) y con ella desarrollaremos los contenidos 1, 2 y 6 .

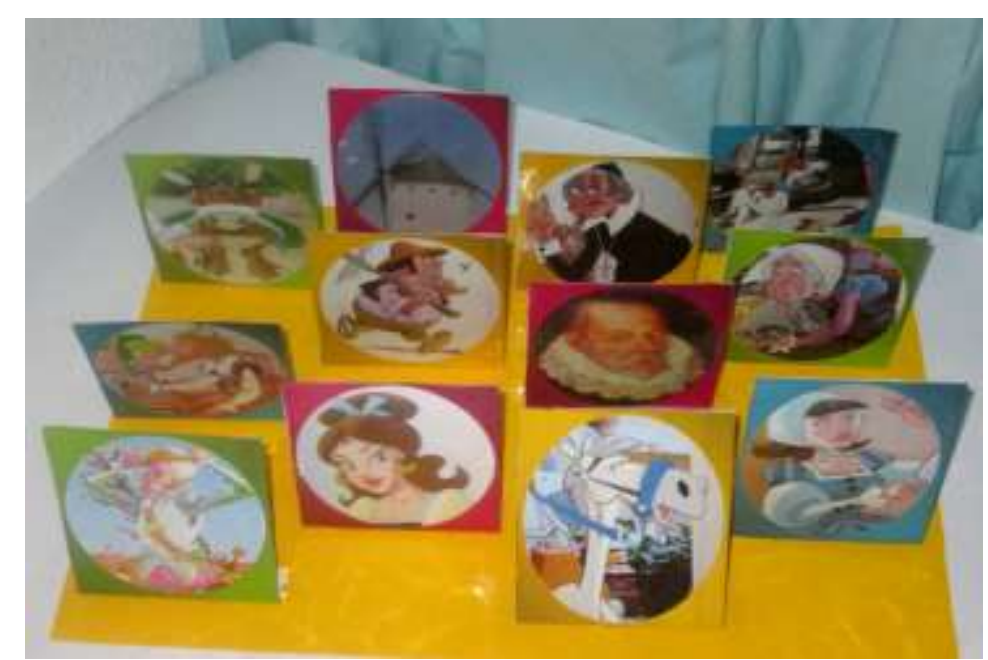

Fotografía 1: Quién es Quién, elaborado con materiales pertenecientes a Albarrán et al (2001), extraídos en Sánchez, Rodríguez y Martínez (2001).

\section{CONOCEMOS A MIGUEL DE CERVANTES...}

Esta actividad consiste en una breve lectura que sintetiza la vida de Miguel de Cervantes, en donde algunas palabras han sido sustituidas por pictogramas. Además, trabajaremos los contenidos 6, 7, 8 y 15 con esta actividad. 


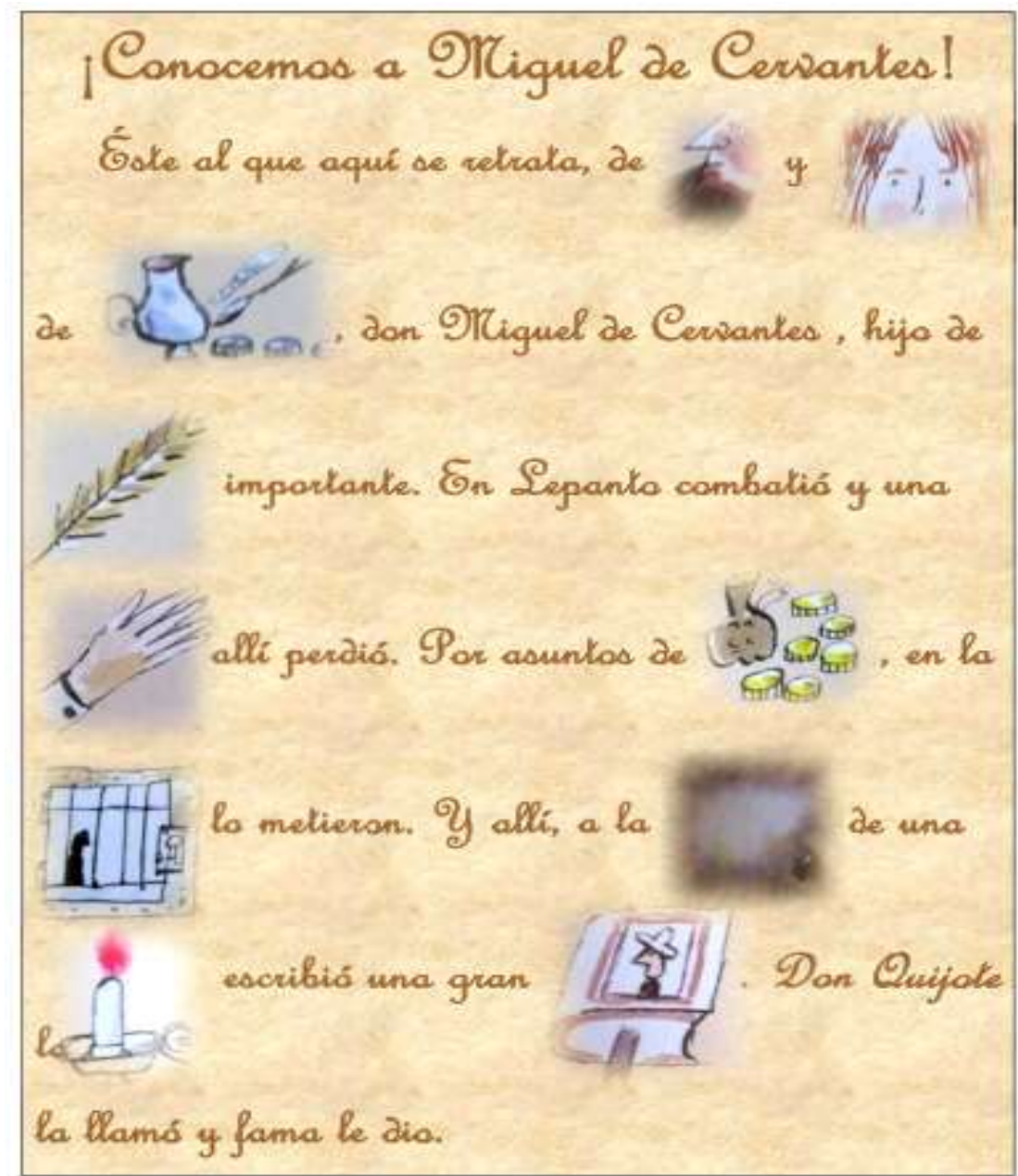

Fotografía 2. ¡Conocemos a Miguel de Cervantes; Texto de Reviejo (2004) e imágenes de Zabala (2004), extraídos en Reviejo, 2004, 6-8.

En esta actividad dividiremos a la clase en 6 grupos. En primer lugar, nos acercaremos a un grupo y le entregaremos un rompecabezas de don Quijote.

El primer grupo formará una imagen y, cuando lo haga, podrá contemplar un dibujo que muestra una de las muchas aventuras de don Quijote. Una vez formada la imagen, realizaremos preguntas a los alumnos para averiguar si conocen dicha aventura. En caso de desconocerla, la explicaremos y la comentaremos brevemente. Posteriormente, procederemos de la misma manera con los otros cinco grupos restantes. Con esta actividad desarrollamos los contenidos $1,2,3,4$ y 6 . 


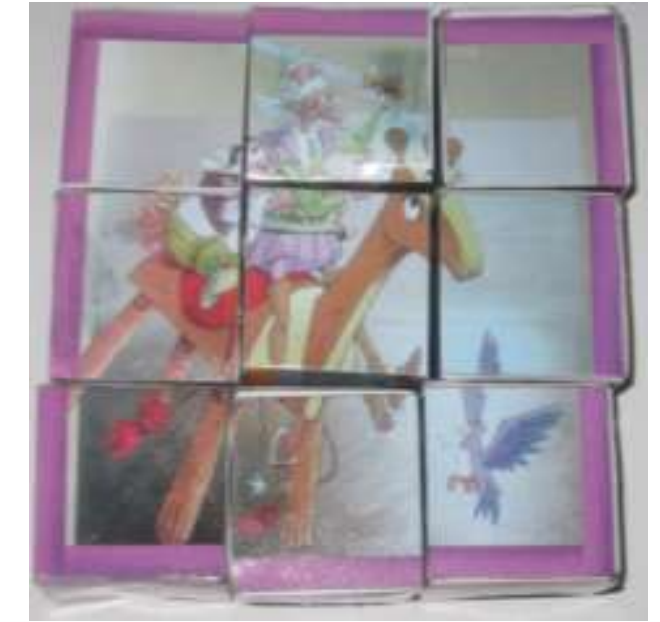

Fotografía 3. Rompecabezas de don Quijote. Elaborado con imágenes de Albarrán et al (2001), extraídas en Sánchez, Rodríguez, y Martínez, $2001,137$.

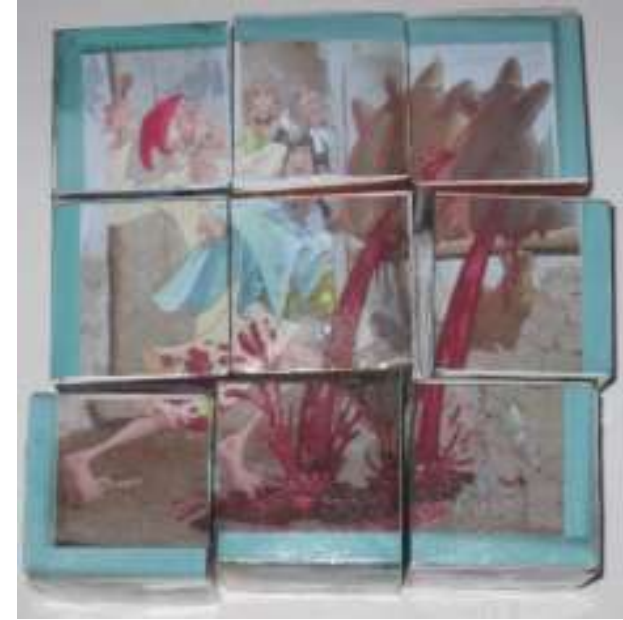

Fotografía 4. Rompecabezas de don Quijote. Elaborado con imágenes de Albarrán et al (2001) extraídas en Sánchez, Rodríguez, y Martínez, 2001, 54-55.

\section{SEGUNDA SESIÓN. ACTIVIDADES DE DESARROLLO}

Con esta sesión, el alumnado desarrollará los objetivos generales de etapa b) y e). Simultáneamente, trabajaremos los contenidos 9, 12, 13 y 17 de la tabla anterior.

\section{¿CÓMO SON DON QUIJOTE Y SANCHO?}

Completa la tabla escribiendo lo contrario:

\begin{tabular}{|c|c|}
\hline Don Quijote & Sancho Panza \\
\hline Intranquilo & \\
\hline & Prudente \\
\hline Culto & \\
\hline
\end{tabular}

Tabla 2

\begin{tabular}{|c|c|}
\hline Don Quijote & Sancho Panza \\
\hline & Incapaz \\
\hline & Racional \\
\hline
\end{tabular}

Tabla 3

Esta actividad no solamente permite al alumnado desarrollar el contenido 12 sino también, conocer las diferentes características entre don Quijote y Sancho. 


\section{¿MB O MP?}

Rodea de rojo mb y de azul mp. Después clasifica las palabras rodeadas. (Con esta actividad trabajamos el contenido 13).

- Don Quijote contempló a lo lejos a un campesino que llevaba un sombrero que relumbraba como el oro. Pensó que era el Yelmo de Mambrino.

- El gigante Malambruno convirtió a la infanta Antonomasia en una mona de bronce $\mathrm{y}$, a Clavijo, su enamorado que siempre la acompañaba, en un cocodrilo de metal.

- Cuando don Quijote y Sancho llegaron a la aldea, sonaban trompeteas, timbales, tambores y campanillas. ¡Con qué fuerza anunciaban las campanas las bodas de Camacho y Quiteria!

\section{¡SIGUE TÚ LA AVENTURA!}

Leeremos al alumnado un fragmento de don Quijote de la Mancha adaptado a su edad. Sin embargo, omitiremos el final de la aventura para que el alumnado recurra a su imaginación y escriba en unas diez líneas el desenlace. Finalmente, el alumnado realizará un dibujo sobre su final. Con esta actividad desarrollamos los contenidos 9 y 17 .

\section{TERCERA SESIÓN. ACTIVIDADES DE DESARROLLO}

La finalidad de esta sesión consiste en desarrollar objetivos de etapa b), e), i) y j) de forma paralela al aprendizaje del de los contenidos 1, 2, 3, 4, 9, 13 y 14 .

\section{DICTADO}

Con este dictado pretendemos desarrollar los contenidos 4, 9 y 13.

En el día del libro animamos a la gente leer. Y se ha elegido este día porque el 23 de abril murieron tres escritores muy famosos: Shakespeare, Cervantes y Garcilaso de la Vega.

Miguel de Cervantes, conocido con el nombre de "El manco de Lepanto", es autor de uno de los libros más importantes: el Quijote. 
En muchas ciudades se celebran "Ferias del Libro". En Cataluña se regala un libro con una rosa. ¡Os invito a leer todos los días aunque sean unas páginas!

\section{EL REFRANERO DE SANCHO PANZA}

Esta actividad, no sólo nos permite trabajar los contenidos 1, 2, 3, 4, 9 y 14, sino también comprender el concepto de refrán. A cada alumno le entregaremos una lámina como la que se muestra a continuación. Las fichas que entregaremos al alumnado son diferentes. No obstante, todas ellas muestran en la parte delantera un refrán de Sancho Panza con un dibujo y unas líneas para que el alumnado escriba el significado de ese refrán. En la parte trasera, los alumnos escribirán dos refranes más que ellos conozcan y realizarán un dibujo de uno de ellos.

Previamente, el día anterior a la realización de esta actividad, pediremos al alumnado que traiga información sobre el significado del refrán de Sancho Panza que le ha sido asignado. De esta manera, el alumnado recurrirá, con ayuda de algún familiar, a la búsqueda de información de su refrán a través de las TIC.

Antes de entregar las láminas, explicaremos el concepto de refrán, pediremos a los alumnos que comenten refranes que previamente hayan escuchado e iremos explicando su significado para que puedan realizar la parte trasera de la lámina. Cuando los alumnos finalicen las láminas, las agruparemos en una carpeta y formaremos un libro llamado El Refranero de Sancho Panza. 


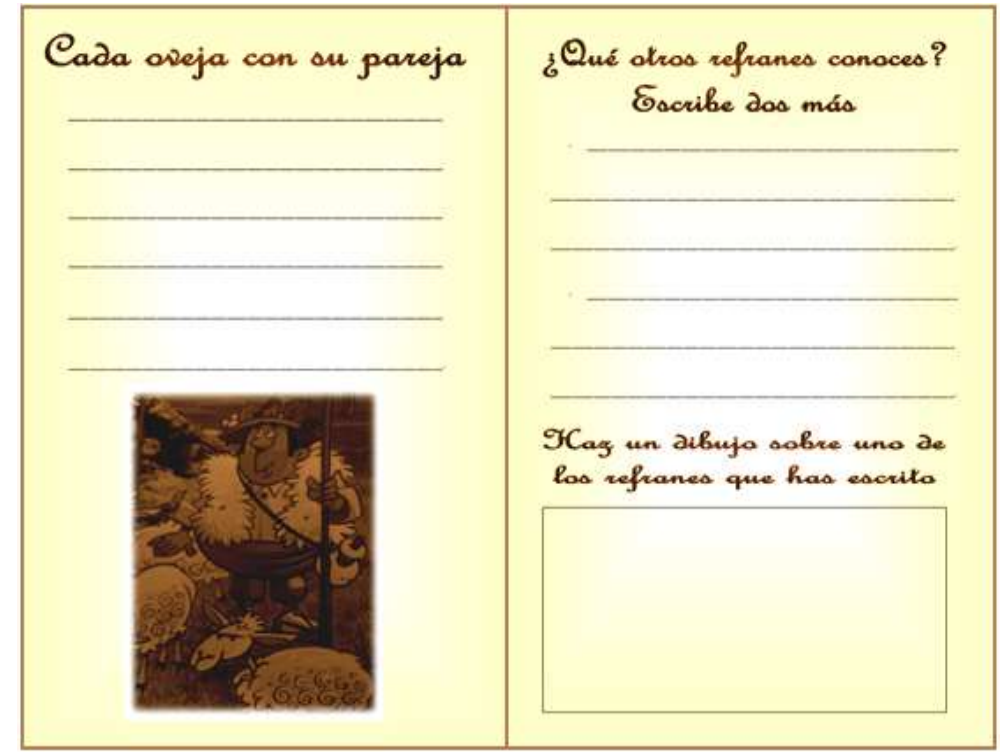

Fotografía 5. Lámina del refranero, elaborado con imagen perteneciente a Albarrán (2001), extraída en Sánchez, Rodríguez y Martínez, 2001, 186.

\section{CUARTA SESIÓN. ACTIVIDADES DE DESARROLLO}

Esta sesión contribuye al desarrollo de los objetivos generales de etapa a), b), e), i) y j). Además, esta sesión contribuirá al desarrollo de los contenidos 1, 2, $3,6,7,8,10,11$ y 14 .

\section{APRENDO VOCABULARIO}

Con esta actividad trabajaremos los contenidos $6,7,8,10$ y 14 . A cada alumno entregaremos una ficha como la que se muestra a continuación. En la parte delantera, cada lámina presenta una palabra extraída del Quijote con un dibujo y unas líneas para que los alumnos escriban el significado de la palabra. Al igual que en la actividad anterior, los alumnos previamente habrán buscado a través de las TIC el significado de la palabra que le ha sido asignada. En la parte trasera, aparece un fragmento adaptado de la obra y un cuadro para que el alumnado realice un dibujo relacionado con el texto. Finalmente, agruparemos todas las láminas y formaremos un libro llamado Diccionario Quijotesco. 


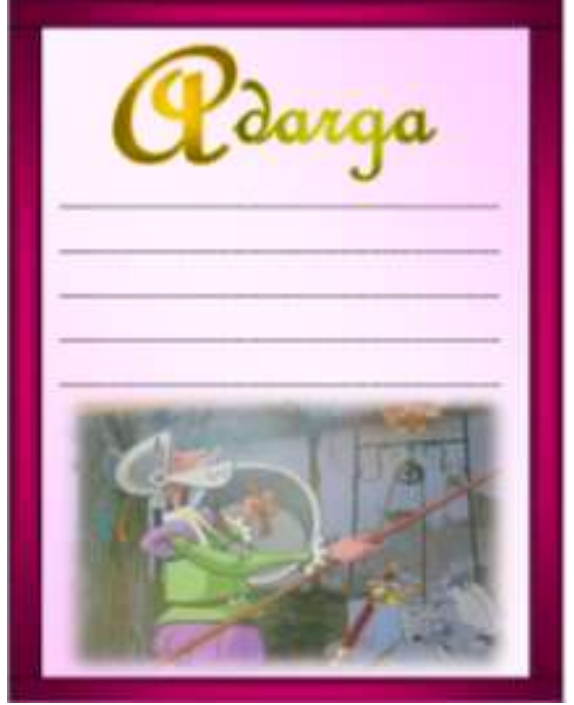

Fotografía 6. Lámina del Diccionario Quijotesco, elaborada con imagen de Albarrán et al (2001), extraída en Sánchez, Rodríguez, y Martínez, 2001, 20.

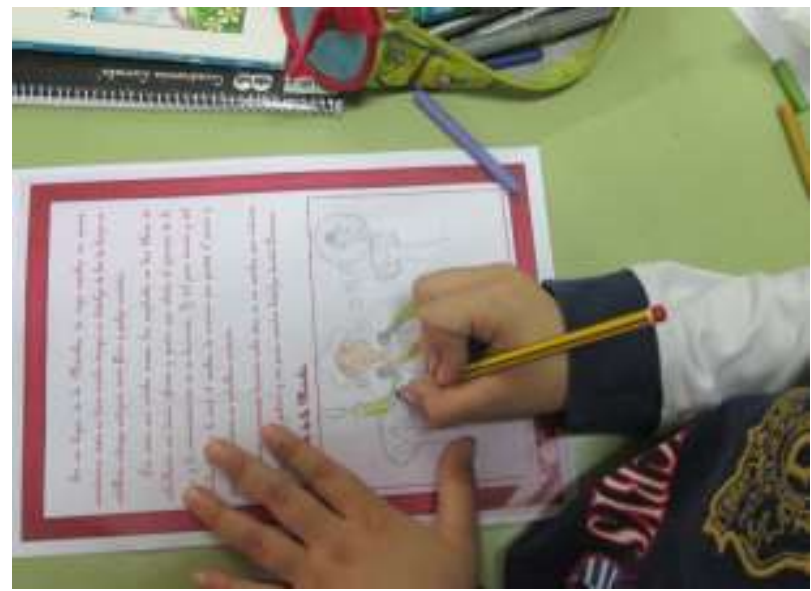

Fotografía 7. (2014). Alumno realizando una lámina del Diccionario Quijotesco.

\section{CONCURSO... ¡BUSCAMOS PALABRAS!}

Una vez terminado el Diccionario Quijotesco, se lo entregaremos al alumnado y realizaremos un concurso consistente en la búsqueda de palabras. También aprovecharemos esta actividad para comentar y explicar algunas de las palabras más relevantes del Quijote. Con esta actividad desarrollamos los contenidos $1,2,3,10$ y 11 .

\section{ACTIVIDADES DE LECTURA}

Esta sección recoge una serie de actividades basadas en el Quijote que tienen por finalidad fomentar el hábito lector, las cuales podemos utilizar en el área de Lengua castellana y Literatura de manera simultánea al desarrollo de esta unidad didáctica. Con estas actividades contribuiremos al desarrollo de los objetivos de etapa a), b), e) y j). 


\section{¡PUNTOS Y COMAS GIGANTES!}

Lee esta poesía con el resto de tus compañeros. Cuando veas una coma gigante da una palmada y cuando veas un punto gigante dos palmadas.

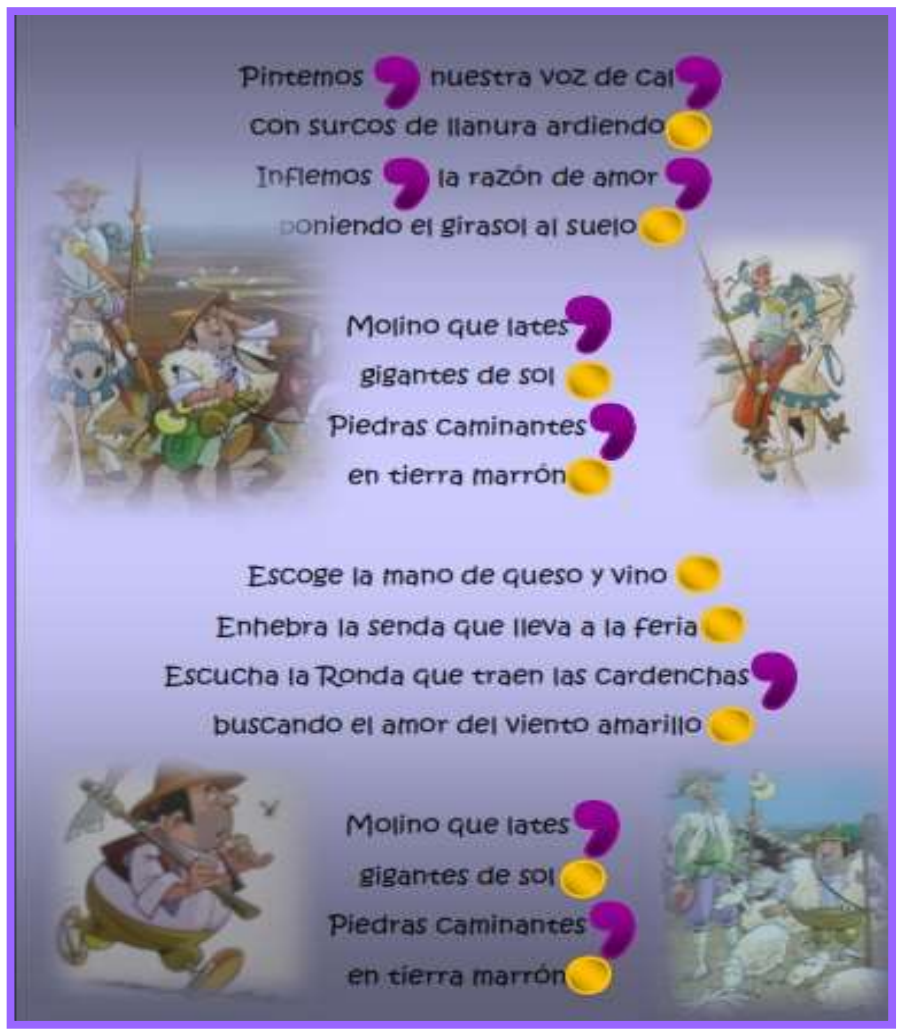

Fotografía 8. Texto de Espinosa (2011), extraído en Don Quijote encuentra a los niños. Imágenes de Albarrán et al (2001), extraídas en Sánchez, Rodríguez, y Martínez, (2001).

En primer lugar, comentaremos las imágenes de la poesía para activar los conocimientos previos que el alumnado posé sobre la novela de Cervantes y, además, explicaremos las palabras de la poesía que el alumnado no entienda con la finalidad de facilitar su comprensión. Por otra parte, esta actividad también tiene por objetivo leer con una entonación y pronunciación adecuada respetando los signos de puntuación. Esta actividad nos permite trabajar los contenidos 4, 6, 8, 15 y 16. 


\section{LECTO-CUCHARA}

Lee la misma poesía del ejercicio anterior con tus compañeros, pero en esta ocasión... ;Con una cuchara introducida en la boca! (Esta actividad, junto con la anterior, tiene por objetivo no solo motivar al alumnado de una manera lúdica hacia la lectura, sino también, mejorar la pronunciación y entonación. Por otra parte, con esta actividad trabajaremos los contenidos 4, 6, 15 y 16.

\section{REPRESENTAMOS UNA OBRA...}

Esta actividad consiste en una pequeña representación teatral en donde los alumnos son los protagonistas. En esta ocasión, podemos recurrir a un texto adaptado sobre el capítulo de Las bodas de Camacho y Quiteria.

Con el objetivo de motivar al alumnado e incrementar su interés hacia la lectura, recurriremos a disfraces que ellos mismos pueden realizar en la hora de Educación Artística. En esta ocasión, para la elaboración de los disfraces hemos recurrido a imágenes de la serie de TVE Don Quijote de la Mancha (1979).

Por otra parte, esta actividad nos permitirá conocer más aventuras de don Quijote y Sancho Panza, así como, desarrollaremos los contenidos 1, 2, 5, 6, 7, 15 y 17.

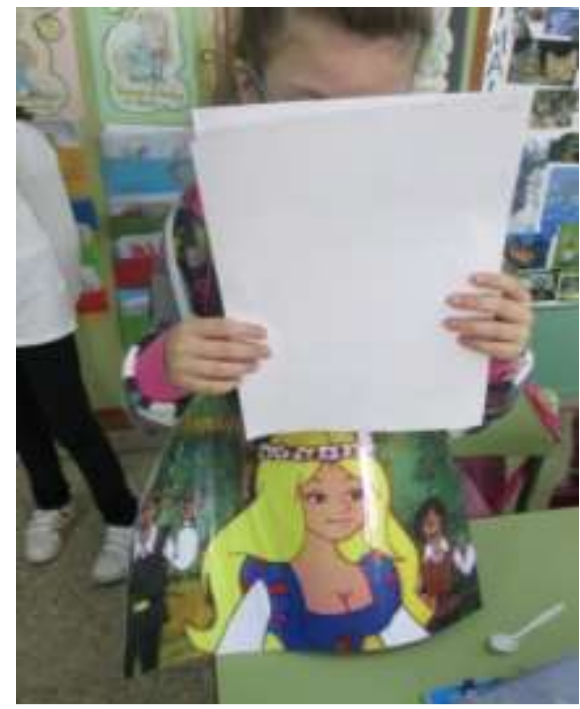

Fotografía 9. (2014). Alumna interpretando a Quiteria.

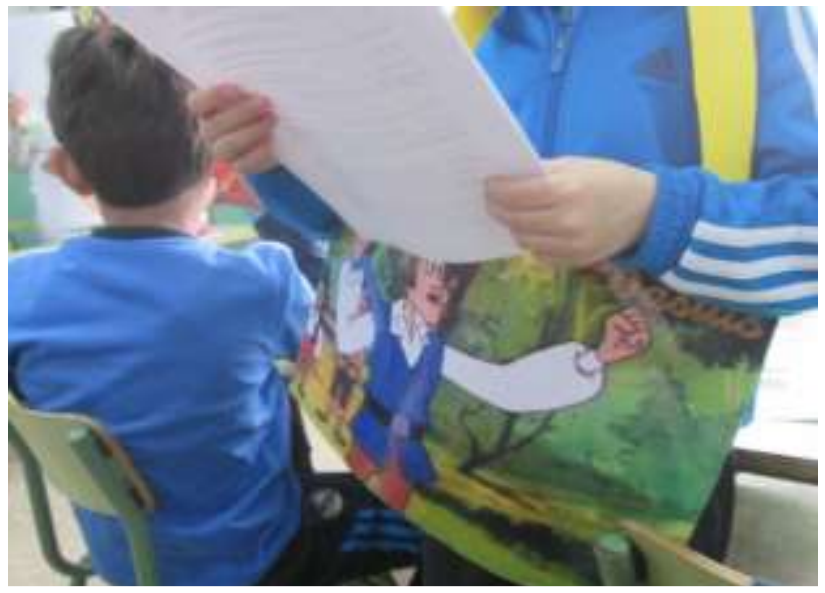

Fotografía 10. (2014). Alumno interpretando a Basilio. 


\section{HACEMOS UN MARCAPÁGINAS...}

Otra de las actividades que podemos llevar a cabo con el alumnado consiste en la elaboración de un marcapáginas, actividad que podría ser realizada durante la hora de Educación Artística. Esta actividad nos permitirá desarrollar los contenidos 6 y 15 .

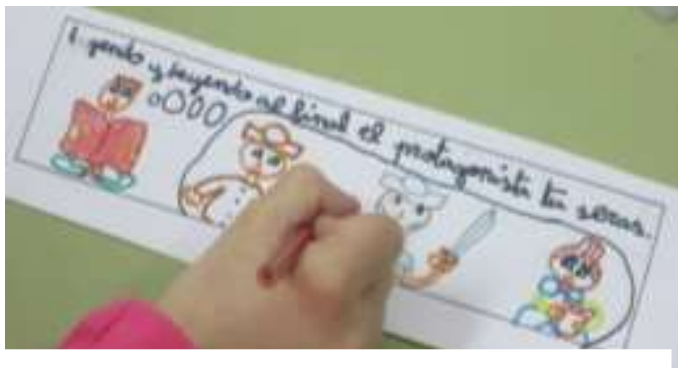

Fotografía 11. (2014). Alumna realizando un marcapáginas sobre don Quijote.

\section{QUINTA SESIÓN. ACTIVIDADES DE EVALUACIÓN}

Para evaluar si el alumnado ha aprendido los contenidos propuestos y, simultáneamente, hemos incrementando su interés y conocimiento hacia la obra, recurriremos a la elaboración de un Trivial que combine los contenidos de lengua programados con preguntas sobre la novela.

\section{CONCLUSIÓN}

Tras el desarrollo y evaluación de esta unidad didáctica, podemos afirmar que se han desarrollado los objetivos y contenidos expuestos en la introducción. Esta unidad no solo ha permitido el aprendizaje de los contenidos programados que se han expuesto en la justificación curricular, sino también, ha contribuido, de manera simultánea, a la motivación hacia la lectura, al fomento del hábito lector y al conocimiento de la obra literaria el Quijote.

En todo momento, las actividades fueron diseñadas y programadas como recursos para alcanzar los contenidos programados en una determinada semana. Sin embargo, los alumnos concibieron desde el primer momento las actividades como juegos novedosos y, mientras no se daban cuenta de que estaban aprendiendo, adquirieron los contenidos programados en esa semana. De hecho, muchos alumnos y alumnas calificaban las actividades propuestas 
como juegos y no paraban de preguntar si el próximo día volveríamos a llevar a cabo juegos en el aula.

Así pues, una de las principales conclusiones a las que he llegado después de llevar a cabo esta unidad didáctica consiste en la necesidad de potenciar al máximo los conocimientos del alumno. En el desarrollo de este trabajo, no solamente hemos desarrollado la unidad didáctica correspondiente para una determinada semana, sino que la hemos ampliado con actividades que permiten fomentar el hábito lector, conocer la obra literaria el Quijote y conocer la cultura manchega. Así pues, los alumnos han adquirido en esa semana una gran cantidad de conocimientos sobre la obra de Miguel de Cervantes que no estaban programados en un principio. Por lo tanto, si relacionamos los contenidos curriculares programados para una determinada fecha con alguna temática o eje vertebrador que resulte interesante al alumnado, potenciaremos al máximo sus conocimientos y los alumnos desarrollaran objetivos adicionales a los que en un primer momento estaban programados.

Esto nos lleva a plantearnos si las unidades didácticas de los libros de texto constituyen el método más adecuado a la hora de impartir los conocimientos. El éxito de esta unidad didáctica no se debe al libro de texto sino a otros materiales alternativos realizados a base de cartulinas, imágenes, plásticos, etc. Una unidad didáctica con un eje vertebrador adicional, como la que aquí se describe, contribuye a potenciar al máximo los conocimientos del alumnado.

Por otra parte, otra conclusión, después de la llevar esta unidad didáctica a un aula, se centra en la importancia de fomentar el hábito lector en los alumnos del primer ciclo de Educación Primaria. Es cierto que uno de los principales objetivos que el alumnado debe alcanzar consiste en leer correctamente con una entonación y pronunciación adecuada diferentes textos, pero igual de importante es fomentar el hábito lector en el alumnado. Si los alumnos no disfrutan de la lectura desde el primer momento y no se les presenta de manera amena y divertida, conforme vayan creciendo y avanzando por los diferentes cursos de la Educación Primaria, no tendrán por hábito leer todos los días, cuando la lectura es la herramienta principal que necesitan para estudiar y aprender los contenidos curriculares. Si en el último ciclo no les motiva la lectura, la concebirán como algo aburrido y, posiblemente, esta sea una de las causas del rechazo al estudio y del fracaso escolar. 
Estas actividades han resultado muy motivadoras para todo el alumnado, incluyendo también a los alumnos con necesidades educativas especiales, ya que en muchas actividadestrabajaban de manera cooperativa con el resto de sus compañeros. Así pues, los alumnos con necesidades educativas especiales fueron partícipes del proceso de su propio aprendizaje gracias a sus compañeros, al mismo tiempo, que éstos se enriquecían de los beneficios que aportaba el trabajo cooperativo.

En definitiva, y teniendo en cuenta los resultados y conclusiones una vez desarrollado este trabajo, podemos afirmar que una unidad didáctica de este tipo, contribuye no solo al aprendizaje de los contenidos propuestos y al desarrollo de la competencia lingüística, que era uno de los principales objetivos que formulábamos al principio, sino también contribuye al aprendizaje de otros contenidos adicionales y al desarrollo del resto de competencias recogidas en el Decreto 54/2014.

\section{BIBLIOGRAFÍA}

Espinosa, M. (2011). Don Quijote encuentra a los niños. Ciudad Real: Obra Social Caja Rural de Ciudad Real.

García, J. (2005). El Quijote en la literatura infantil española. Revista Didáctica (Lengua y Literatura), 17, 132-133.

García, P. (2005). El Quijote: modelos de libertad vivencial y creativa para las aulas. Revista Didáctica (Lengua y Literatura), 17, 122-127.

Mendoza, A. (2006). Cervantes en su obra: la transformación literaria de un currículo vitae. Revista Didáctica (Lengua y Literatura), 17, 193-195.

Real Decreto 126/2014, de 28 de febrero, por el que se establece el currículo básico de la Educación Primaria.

Reviejo, C. (2004). Don Quijote de la Mancha. Pinto: SM.

Rey, A. (2006). Los clásicos en la enseñanza del español. Revista Multiárea. Revista de didáctica, 1, 2006.

Sánchez, J. C., Rodríguez, N. y Martínez, A.M. (2001). Don Quijote de la Mancha. Madrid: Susaeta. 